\title{
вMJ Global Health Abortion-related near-miss morbidity and mortality in 43 health facilities with differences in readiness to provide abortion care in Uganda
}

\author{
Susan Atuhairwe (D) , ${ }^{1,2}$ Kristina Gemzell-Danielsson, ${ }^{3}$ Josaphat Byamugisha, ${ }^{1}$ \\ Frank Kaharuza, ${ }^{4}$ Nazarius Mbona Tumwesigye, ${ }^{5}$ Claudia Hanson (1) 6,7
}

To cite: Atuhairwe S, Gemzell-Danielsson K, Byamugisha J, et al. Abortionrelated near-miss morbidity and mortality in 43 health facilities with differences in readiness to provide abortion care in Uganda. BMJ Global Health 2021;6:e003274. doi:10.1136/ bmjgh-2020-003274

Handling editor Sanni Yaya

Received 28 June 2020

Revised 12 January 2021

Accepted 20 January 2021

Check for updates

C Author(s) (or their employer(s)) 2021. Re-use permitted under CC BY-NC. No commercial re-use. See rights and permissions. Published by BMJ.

For numbered affiliations see end of article.

Correspondence to Dr Susan Atuhairwe; atususan96@gmail.com

\section{ABSTRACT}

Introduction With a view to inform policy for improved postabortion care, we describe abortion-related nearmiss and mortality by sociodemographic risk factors and management options by pregnancy trimester in Uganda. Methods This secondary data analysis used an adapted WHO near-miss methodology to collect cross-sectional maternal near-miss and abortion complications data at 43 health facilities in Central and Eastern Uganda in 20162017. We computed abortion severe morbidity, near-miss and mortality ratios per 100000 live births, and described the proportion of cases that worsened to an abortion near-miss or death, stratified by geographical region and trimester. We tested for association between independent variables and abortion near-miss, and obtained prevalence ratios for association between second trimester nearmiss and independent demographic and management indicators. We assessed health facility readiness for postabortion care provision in Central and Eastern regions. Results $0 f 3315$ recorded severe abortion morbidity cases, 1507 were near-misses. Severe abortion morbidity, near-miss and mortality ratios were 2063, 938 and 23 per 100000 live births, respectively. Abortion-related mortality ratios were 11 and 57 per 100000 in Central and Eastern regions, respectively. Abortion near-miss cases were significantly associated with referral $(p<0.001)$. Second trimester had greater abortion mortality than first trimester. Eastern region had greater abortion-related morbidity and mortality than Central region with facilities in the former characterised by inferior readiness to provide postabortion care.

Conclusions Uganda has a major abortion near-miss morbidity and mortality; with mortality higher in the second trimester. Life-saving commodities are lacking especially in Eastern region compromising facility readiness for postabortion care provision.

\section{INTRODUCTION}

Unsafe abortion is a major reproductive health challenge contributing to $7.9 \%$ global and $9.6 \%$ regional maternal deaths. ${ }^{1}{ }^{2}$ Over $75 \%$ of all abortions in sub-Saharan Africa, Uganda inclusive, are unsafe due to restrictive

\section{Key questions}

What is already known?

- The WHO near-miss indicator is proposed to assess the quality of maternal services and several studies provide evidence on the usefulness of the concept using the original and adapted WHO near-miss approaches.

- A systematic review of 70 studies from 28 countries published in 2018 estimates an abortion near-miss rate of $9 \%$, and a mortality rate of $1.5 \%$ among abortion-related hospital admissions.

What are the new findings?

- This is the first study to provide detailed characterisation of abortion near-miss by pregnancy trimester.

- Using the adapted WHO near-miss criteria, we found a higher abortion-related mortality in the second compared with first trimester. Referred women were more likely to develop abortion near-miss. Women who had a near-miss abortion event in the second trimester had a lesser prevalence of uterine evacuation or manual vacuum aspiration than spontaneous expulsion compared with women in the first trimester (crude prevalence ratio (cPR) $0.69,95 \% \mathrm{Cl} 0.51$ to 0.93$)$.

- The Eastern region of Uganda had less readiness for Post Abortion Care, with higher abortion-related morbidity and mortality. Although both results come from independent cross-sectional data and precluding causal inference, our result points to the importance of providing adequate services for women with abortion complications.

abortion laws. ${ }^{3} 4$ Furthermore, low socioeconomic status, low literacy rates and low contraceptive uptake are associated with high unsafe abortion rates and severe abortion morbidity (SAM).$^{5-8}$ Abortion-related deaths are largely preventable if patients receive timely appropriate care such as postabortion care (PAC). ${ }^{9}{ }^{10} \mathrm{PAC}$ is essential life-saving care to address the impact of abortion-related 


\section{Key questions}

What do the new findings imply?

- There is a major burden of abortion near-miss and mortality particularly in low-income settings.

- Women with second trimester abortion complications need urgent attention to avert severe abortion-related complications and deaths.

- Provision of essential drugs and supplies is crucial to averting abortion-related near-miss and deaths.

complications which are primarily due to 'unsafe' abortions.

Assessing the incidence of severe abortion and abortion-related mortality is important to gauge the quality and effectiveness of PAC. To standardise the assessments of morbidity, WHO defined a near-miss as 'a woman who nearly died but survived a complication that occurred during pregnancy, childbirth or within 42 days of termination of pregnancy'. ${ }^{11}$ Abortion near-miss (ANM), a subset of maternal near-miss, may be the result of delays in accessing safe abortion care as well as delays in getting PAC when complications arise. While spontaneous and safe abortions are less likely to have near-miss complications (and deaths) than unsafe induced abortions, PAC addresses both. ${ }^{12}$ Quality PAC is dependent on appropriate equipment, commodities, laboratory tests, guidelines and trained staff; this averts further harm and improves patient survival.

ANM is both a success and a failure with respect to quality of care. A success because the woman has been saved in extremis by hospital teams, especially if she arrived in a very severe condition at the facility. A failure, because she became so severely ill. ${ }^{13}$ Still, ANM occurrence and mortality is a valuable indicator for health systems' planning, case management strategies and evaluation of healthcare provided. Previous research proposed ANM incidences per 100000 live births between 200 and 450 and abortion-related mortality ratio (AMR) about 85 per 100000 live births in Africa. ${ }^{14-17}$

PAC was introduced in Uganda in the early 1990s as part of basic and comprehensive emergency obstetric care (EmOC) packages. $^{18} 19$ PAC is offered by both midwives and doctors from primary level health facilities and hospitals. ${ }^{20}$ Paul et al published research on barriers that women in Uganda face in accessing PAC services which lead to more severe complications. ${ }^{21}$ Little is known, however, if incidence and mortality differ in relation to PAC services by country region and to which extent complication rates are driven by sociodemographic status, reproductive characteristics or management options by pregnancy trimester. ${ }^{17}$ Our study from 43 facilities in two distinct regions of $\mathrm{Uganda}^{22}$ aims to assess abortion-related morbidity and mortality by region, and therewith differences in the availability of PAC servicesand by sociodemographic and reproductive characteristics including trimester in Uganda.

\section{METHODS}

\section{Study design, setting and participants}

We collected cross-sectional data on maternal near-miss as part of a cluster randomised two-arm trial to assess the impact of a 1 day competency-based training 'Helping Mothers Survive: Bleeding after Birth' on morbidity and mortality due to postpartum haemorrhage (PPH). The primary trial details are reported elsewhere. ${ }^{23}$ The study was conducted in 11, and 7 districts in Central and Eastern regions of Uganda, respectively, at 22 hospitals, and 21 high case load health centres; 9 were private not for profit (PNFP) and 34 public. In each district, taken as a cluster, we included all public hospitals and randomly sampled health centres and PNFP health facilities with more than 400 deliveries per year. Ministry of Health Uganda recommended the selected districts and all health facilities offer at least basic EmOC services. Data collection run from June 2016 to September 2017.

\section{Data collection}

We used the WHO near-miss form to collect data of all maternal near-miss events, and deaths which took place in the selected health facilities. ${ }^{24}$ The data collection form was amended and included severe abortion complications, see online supplemental appendix I, as a screening question to ensure that these events were captured consistently. Details of categories for organ dysfunction, critical interventions, and other data collected are reported elsewhere. ${ }^{23}$

At each health facility, two of the midwives, selected as data collectors received a 1-day training on nearmiss methodology and the data collection process. We collected data prospectively from several service points at the health facilities including (1) antenatal, labour and postnatal ward, (2) female and surgical ward, (3) laboratory and (4) theatre to ensure that all cases of near-miss and maternal deaths were included. A standard protocol was used to abstract information from the patient's clinical case notes and registries for admission, birth, theatre, laboratory and discharge. From the paper forms, the data collectors entered data onto a tablet-based application (Lenovo A3500-F) and uploaded onto the cloud server biweekly using Open Data Kit Collect software application. Data on the total number of live births in the facilities were collected through monthly telephone calls and verified during supervision visits. The data collectors were supported through biweekly supervision visits and regular telephone calls to ensure complete and correct abstraction of data.

This paper uses only the data on maternal near-misses admitted as abortion-related complications. An abortion was defined as termination of a pregnancy less than 28 weeks gestation age. We extracted data for women coded as having abortion complications from those with severe maternal morbidity. Women with ectopic pregnancy or gestation age above 27 weeks were excluded, viability in Uganda begins at 28 weeks. ${ }^{19}$ Since PPH and abortion are both bleeding complications, we screened the PPH cases 
to identify the abortion cases that were miscoded as PPH using a gestation age less than 28 weeks. Cases that were coded as abortion cases but where the gestation age was missing were not excluded from the data set (see online supplemental appendix II).

We assessed for PAC provision health facility readiness at the 43 health facilities from February to April 2016 using an adapted Uganda health facility assessment tool. Components therein are very similar to the WHO service availability and readiness assessment tool, ${ }^{25}$ however, we did not collect information on whether the abortion was spontaneous or induced, and provision of family planning services as these were not captured in the primary study tool. Key items measured that influence access and availability to PAC services at all the health facilities included: (1) uterotonics like misoprostol and oxytocin; (2) manual vacuum aspiration (MVA) sets; (3) intravenous fluids; (4) parenteral antibiotics; (5) ability to provide PAC services 24 hours a day, 7 days a week $(24 / 7)$; (6) referral capability (motorised transport for referral, health provider accompanying a referral); (7) communication means; and for health facilities offering comprehensive EmOC; (8) blood transfusion services and (9) surgical/laparotomy capability.

Service readiness components like equipment and commodities were verified by checking their presence on the wards, pharmacy, laboratory and the health facility stores. Health facilities' ability to provide PAC services $24 / 7$ was verified with checking duty schedules, ward and theatre registers for the previous 3 months. We inquired about the presence of motorised transport at the health facility, and whether the most recent referral to a higher facility had been accompanied by a health provider to check the referral capability.

\section{Outcomes and explanatory variables}

The main outcome, ANM, was defined using our adapted WHO near-miss criteria as a case of severe abortion complication with either organ dysfunction, severe sepsis, blood transfusion or laparotomy. Given the paucity of blood products in low to middle income countries, the threshold for massive blood transfusion was reduced to two units down from the five units recommended by WHO. ${ }^{1426} 27$ Other outcomes were:

- SAM ratio (SAMR) as the number of all cases with severe abortion complications per 100000 live births.

- ANMR as the number of abortion-related near-miss cases per 100000 live births.

- AMR as the number of maternal deaths due to abortion per 100000 live births.

Independent variables included background characteristics like gestation age based on weeks of amenorrhoea, patient's age in completed years, number of pregnancies and timing of onset of complications. Reproductive and institutional factors like HIV status, referral status (referred into the facility), type of health facility and ownership. We also collected information on complications including infection, organ dysfunction and maternal death; as well as management options like types of uterine evacuation, uterotonics administered, and additional interventions, for example, blood transfusion, number of blood transfusion units administered and laparotomy, all abstracted from the patient's clinical case notes.

\section{Statistical analysis}

Statistical analysis was performed using Stata V.14. We present the number of women with severe abortion complications, ANM, abortion-related deaths; and SAMR, ANMR and AMR for all women in the study, then segregated by region. We also present the proportions of SAM that had ANM or abortion-related deaths by region and pregnancy trimester. The estimates were not weighted for region. We designated health facility as a primary sampling unit and assigned all health facilities the same weight using STATA command svyset (pw=wgt), psu(id3) singleunit (centred).

Background characteristics and categorical outcomes were presented with descriptive statistics. Continuous variables were summarised using means $(\mathrm{SD})$ or medians (IQR) and categorical variables using proportions (CIs). Pearson's $\chi^{2}$ was used to test the difference between severe abortion complications cases and those that progressed to be ANM across different sociodemographic, reproductive and institutional characteristics. We computed $95 \%$ CIs and statistical significance established at $\mathrm{p}<0.05$. We excluded women with missing data for gestation age and unrecorded HIV status in the statistical test computation for background and reproductive characteristics comparison among near-miss cases to avoid misinterpretation of findings.

We then described the proportion of women with severe abortion complications or ANM that suffered complications such as infection, organ dysfunction, maternal death and the management options received including type of uterine evacuation, uterotonics administered, blood transfusion and when a laparotomy was performed. To examine the association between first and second trimester ANM and background characteristics, reproductive factors, institutional factors, types of complications and management options, we did multiple generalised linear models with binomial family and log link to obtain unadjusted prevalence ratios effect estimates.

Regarding health facility readiness for PAC, we computed the percentage of facilities that fulfilled each readiness indicator, for all health facilities and for central and eastern region. Performed Pearson $\chi^{2}$ or Fischer's exact tests to compare PAC health facility readiness between the central and eastern region.

\section{Role of the funding source}

The funder had no role in study conceptualisation, data collection, analysis and manuscript writing. All authors had full access to the study data and the corresponding author had final responsibility for the decision to submit for publication. 


\section{RESULTS}

We extracted data of 3315 (25.8\%) SAM cases from the total of 12843 severe maternal complications collected over a period of 15 months from 43 health facilities. Forty five percent $(\mathrm{n}=1507)$ of the 3315 women with severe abortion-related complications fulfilled the criteria as ANM cases (see online supplemental appendix II). During the same period, there were a total of 160701 live births at the study sites with the Central and Eastern regions having 118674 and 42027 live births, respectively.

The facility SAMR, ANMR and AMR were 2063, 938 and 23 per 100000 live births, respectively (see table 1 ). The Eastern region had an SAMR of 3641 and ANMR of 1785 per 100000 live births; while the Central region had an SAMR of 1504 and ANMR of 638 per 100000 live births. Thirty-seven women died from abortion complications with an AMR of 11 vs 57 per 100000 live births in Central and Eastern region, respectively. Of the documented 1459 and 1044 first and second trimester severe abortion complications, $589(40.4 \%)$ and $499(47.8 \%)$, respectively, developed into an ANM and $5(0.3 \%)$ and $21(2.0 \%)$, respectively, died.

In the Central region, out of 625 and 543 first and second trimester women with SAM, $284(45.4 \%)$ and $212(39.0 \%)$, respectively, developed into ANM and $1(0.2 \%)$ and $6(1.1 \%)$, respectively, died. While the Eastern region, had $36.6 \%$ and $57.3 \%$ of the SAM in the first and second trimester respectively develop ANM, and death occurred in $0.5 \%$ and $3.0 \%$ in the first and second trimester, respectively. The mean age of participants was 26 years (SD 7), and the median number of pregnancies was three (IQR 2-5) (see table 2). Patients referred into the health facilities were more likely to progress to develop an ANM $(\mathrm{p}<0.001)$. Regarding complications seen and management options in table 3, only 243 women $(16 \%)$ with ANM had an infection and $76 \%$ presented with organ dysfunction. Surgical uterine evacuation using MVA or curettage (D\&C) was performed in $58 \%$ of ANM cases, $41 \%$ had a spontaneous expulsion while only $1 \%$ got medical evacuation. Oxytocin was the commonly administered uterotonic in $58 \%$ of the cases, followed by misoprostol in $40 \%$.

Only $42 \%$ of all ANM cases received a blood transfusion, and $47 \%$ of patients who received blood transfusion had their haemoglobin $(\mathrm{Hb})$ checked at discharge. The median $\mathrm{Hb}$ at discharge was $72 \mathrm{~g} / \mathrm{L}$ (IQR 58-90). Majority (58\%) of the near-miss cases only got one unit of blood, $40 \%$ got 2-4 units of blood and $2 \%$ received five or more units.

Laparotomy was performed in 27 patients; nine and 11 of whom were in the first and second trimester, respectively, with gestation age not specified in seven patients (table 3 ). The indications for laparotomy included: uterine perforation in 10, 8 had pelvic abscess, 3 got subtotal hysterectomy, 1 patient with missed abortion and disseminated intravascular coagulopathy had a hysterotomy, 2 patients with induced abortion had vesicovaginal fistula and 1 of them in addition had a rectovaginal fistula. Majority
$(52 \%)$ of these laparotomies were performed between 3 and 12 hours from admission. The prevalence of ANM complications developing after having been admitted at least 12 hours was $37 \%$ (cPR 1.37, 95\% CI 1.07 to 1.76 ) higher in women with second trimester ANM compared with women with first trimester ANM (table 4). We also observed an association between second trimester ANM and the methods used for uterine evacuation. Women with second trimester ANM had a 31\% (cPR 0.69, 95\% CI 0.51 to 0.93 ) lesser prevalence of uterine evacuation or MVA as opposed to a spontaneous expulsion compared with women with first trimester ANM.

All 43 health facilities could offer PAC services 24/7. Majority of the health facilities had intravenous fluids (93\%), parenteral antibiotics $(86 \%)$ and oxytocin (86\%) while misoprostol $(42 \%)$ was grossly lacking with MVA sets in only $70 \%$ of them. Approximately $74 \%$ of the health facilities had motorised transport for referral; and only $42 \%$ had a health provider accompanying the referral. A comparison of the central and eastern regions for PAC readiness revealed that the central region had significantly more MVA sets $(\mathrm{p}=0.003)$, motorised transport for referral $(\mathrm{p}=0.004)$ and health provider accompaniment of referrals $(\mathrm{p}=0.034)$. Availability of uterotonics, intravenous fluids, parenteral antibiotics, communication means, blood transfusion services and surgical/laparotomy capability did not significantly differ by region (table 5).

\section{DISCUSSION \\ Main findings}

This study reveals the high burden of abortion-related morbidity and mortality in Uganda which agrees with evidence from similar settings with highly restrictive abortion laws. ${ }^{28}$ Close to $1.8 \%$ of women with SAM died particularly those in the second trimester. The Eastern region of the country had less PAC readiness, only $40 \%$ of facilities had MVA kits compared with $86 \%$ in the Central region $(p=0.003)$ but also had worse abortion-related near-miss and mortality outcomes.

A WHO multicountry survey of 23 countries cites Uganda second to Afghanistan in reporting abortionrelated severe maternal outcomes. ${ }^{2}$ Uganda has one of the highest fertility rates in the sub-Saharan region hence more pregnancy-related complications. ${ }^{29}$ We report a high ANMR of 938 per 100000 live births, which can be attributed to the fact that we modified the near-miss definition to also include those with at least two instead of at least five blood transfusions. ${ }^{1415}$ Despite the huge morbidity burden shown in this study, our AMR (23 per 100000 live births) is lower compared with other countries like Zambia (52 per 100000 live births), and Nigeria (85 per 100000 live births). ${ }^{101415}$

PAC is globally accepted as life-saving care to women with abortion complications. ${ }^{30}$ In Uganda, PAC is recognised as a core signal function from health centre III level, and trained health providers including midwives 


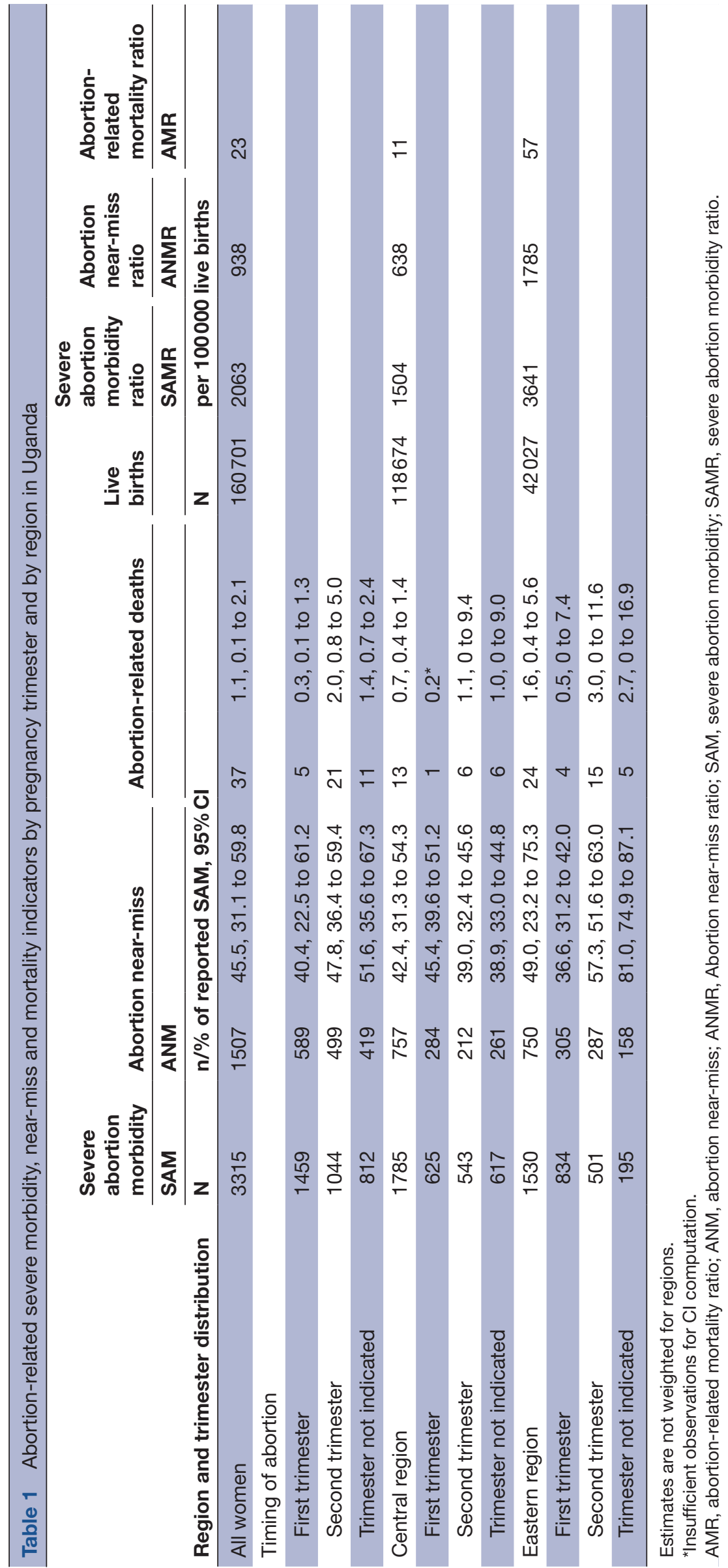

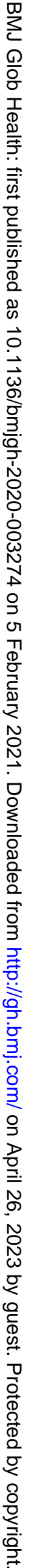


Table 2 Sociodemographic, reproductive and institutional characteristics of severe abortion morbidity and abortion nearmiss in Uganda

\begin{tabular}{|c|c|c|c|c|c|}
\hline Characteristics & $\begin{array}{l}\text { Severe abortion } \\
\text { complications } \mathrm{n}^{*} \\
\mathrm{~N}=3315\end{array}$ & $\begin{array}{l}\text { Abortion near- } \\
\text { miss cases } \mathrm{n} \dagger \\
\mathrm{N}=1507\end{array}$ & $\begin{array}{l}\text { Abortion near-miss } \\
\text { row } \% \neq \\
(95 \% \mathrm{Cl})\end{array}$ & $\chi$ & P value§ \\
\hline Age group (years) & & & & 8.74 & 0.22 \\
\hline$<18$ & 180 & 94 & 52 (37 to 67$)$ & & \\
\hline $18-24$ & 1335 & 572 & 43 (29 to 58$)$ & & \\
\hline $25-29$ & 729 & 334 & 46 (33 to 59$)$ & & \\
\hline $30-34$ & 542 & 260 & 48 (36 to 60$)$ & & \\
\hline $35+$ & 529 & 247 & $47(29$ to 65$)$ & & \\
\hline Number of pregnancies & & & & 9.75 & 0.22 \\
\hline 1 & 752 & 313 & $42(28$ to 56$)$ & & \\
\hline 2 & 589 & 263 & $45(30$ to 60$)$ & & \\
\hline 3 & 482 & 216 & $45(32$ to 59$)$ & & \\
\hline 4 & 369 & 167 & $45(32$ to 59$)$ & & \\
\hline 5 or more & 1123 & 548 & $49(33$ to 65$)$ & & \\
\hline Gestation age & & & & 13.669 & 0.339 \\
\hline First trimester & 1459 & 589 & $40(23$ to 61$)$ & & \\
\hline Second trimester & 1044 & 499 & $48(36$ to 59$)$ & & \\
\hline Trimester not indicated & 812 & 419 & $52(36$ to 67$)$ & & \\
\hline HIV status & & & & $10.18^{\star \star}$ & $0.12^{\star \star}$ \\
\hline Negative & 2388 & 942 & $39(26$ to 55$)$ & & \\
\hline Positive & 148 & 78 & $53(37$ to 68$)$ & & \\
\hline Not recorded & 779 & 487 & $63(44$ to 78$)$ & & \\
\hline Timing of complications & & & & 7.75 & 0.07 \\
\hline $\begin{array}{l}\text { At arrival or within } 12 \\
\text { hours }\end{array}$ & 3253 & 1468 & $45(31$ to 60$)$ & & \\
\hline Developed after 12 hours & 62 & 39 & $63(46$ to 77$)$ & & \\
\hline Referral status & & & & 198.11 & $<0.001$ \\
\hline Not referred & 2880 & 1173 & $41(28$ to 55$)$ & & \\
\hline Referred†† & 435 & 334 & $77(64$ to 86$)$ & & \\
\hline Type of health facility & & & & 34.22 & 0.42 \\
\hline Health Centre & 1204 & 628 & $52(34$ to 70$)$ & & \\
\hline Hospital & 2111 & 879 & $42(25$ to 61$)$ & & \\
\hline Ownership of health facility & & & & 18.7 & 0.40 \\
\hline Public & 2675 & 1265 & $47(31$ to 64$)$ & & \\
\hline Private & 640 & 242 & 38 (25 to 53$)$ & & \\
\hline
\end{tabular}

*Number of women with severe abortion complications in each row category, the denominator includes abortion near-miss cases as well .

†Number of abortion near-miss cases in each row category.

¥Proportion of women with abortion near-miss out of the total with severe abortion complications in each row category.

$\S$ Using the Pearson $\chi^{2}$ to test difference in the proportion of all severe abortion complications that are near-miss across different sociodemographic, reproductive and institutional characteristics.

ПExcludes patients where the trimester was not indicated.

${ }^{* *}$ Excludes patients that did not have a recorded HIV status.

††Patients referred into the health facility for management of abortion complications.

can manage bleeding complications by performing MVA especially for first trimester abortions. This deliberate effort by the Uganda Ministry of Health to task share in patient management probably contributes to the reduced mortality from abortion complications. ${ }^{19}$

Our study shows that ANM morbidity and mortality is greater in the Eastern region compared with the 
Table 3 Postabortion complications and management options for women with severe abortion complications and abortion near-miss

\begin{tabular}{|c|c|c|c|}
\hline Characteristics & $\begin{array}{l}\text { Complication/ } \\
\text { management option } n^{*}\end{array}$ & $\begin{array}{l}\text { Proportion (\%) of complication } \\
\text { among severe abortion } \\
\text { complications } \dagger \\
(95 \% \text { Cl) } \mathrm{N}=3315\end{array}$ & $\begin{array}{l}\text { Proportion (\%) of } \\
\text { complication among abortion } \\
\text { near-miss } \\
(95 \% \mathrm{Cl}) \mathrm{N}=1507\end{array}$ \\
\hline \multicolumn{4}{|l|}{ Complications } \\
\hline Maternal deaths & 37 & $1(0$ to 3$)$ & N/A \\
\hline Infection & 243 & 7 (4 to 12$)$ & 16 (10 to 24$)$ \\
\hline Organ dysfunction & 1138 & 34 (23 to 48$)$ & 76 (65 to 84$)$ \\
\hline \multicolumn{4}{|l|}{ Management options } \\
\hline \multicolumn{4}{|l|}{ Types of uterine evacuation } \\
\hline Spontaneous expulsion & 1086 & 35 (24 to 47$)$ & 41 (27 to 56$)$ \\
\hline Evacuation/MVA & 2038 & 65 (53 to 75$)$ & 58 (43 to 72$)$ \\
\hline Medical & 17 & 1 (0 to 1$)$ & 1 (0 to 3 ) \\
\hline \multicolumn{4}{|l|}{ Uterotonics administered } \\
\hline Misoprostol & 950 & 33 (23 to 46$)$ & 40 (27 to 54$)$ \\
\hline Oxytocin & 1826 & 64 (52 to 75$)$ & 58 (44 to 71$)$ \\
\hline Other uterotonics & 69 & $2(1$ to 11$)$ & $2(1$ to 7$)$ \\
\hline \multicolumn{4}{|l|}{ Additional interventions } \\
\hline \multicolumn{4}{|l|}{ Blood transfusion } \\
\hline Yes & 636 & $-\S$ & 42 (24 to 62$)$ \\
\hline \multicolumn{4}{|l|}{ Blood units received $(n=636)$} \\
\hline 1 & 3679 & $-\S$ & $58(45 \text { to } 69)^{\star *}$ \\
\hline 2 & 188 & $-\S$ & $30(23 \text { to } 37)^{\star *}$ \\
\hline $3-4$ & 64 & $-\S$ & $10(5 \text { to } 18)^{\star \star}$ \\
\hline 5 or more & 10 & $-\S$ & $2(1 \text { to } 3)^{\star \star}$ \\
\hline Units unknown & 7 & $-\S$ & $1(0 \text { to } 3)^{\star \star}$ \\
\hline \multicolumn{4}{|l|}{ Laparotomy $(n=27)$} \\
\hline $\begin{array}{l}\text { Done }<3 \text { hours from } \\
\text { admission }\end{array}$ & 9 & $-\S$ & 33 (12 to 64$)$ \\
\hline $\begin{array}{l}\text { Done } 3-12 \text { hours from } \\
\text { admission }\end{array}$ & 14 & $-\S$ & $52(21$ to 81$)$ \\
\hline $\begin{array}{l}\text { Performed after } 12 \text { hours of } \\
\text { admission }\end{array}$ & 4 & $-\S$ & 15 (5 to 36$)$ \\
\hline
\end{tabular}

Pearson $\chi^{2}$ was the statistical test used however we do not present the $\chi^{2}$ or $p$ value .

*Number of all women with each row characteristic.

†Proportion of severe abortion complications with row characteristic out of the total number of severe abortion complications, severe abortion complications also include the near-miss cases.

‡Proportion of abortion near-miss cases with row characteristic out of the total number of abortion near-miss cases.

§All patients who received additional interventions (blood transfusion and laparotomy) were near-miss cases.

ףWomen who received only one unit of blood transfusion but had other near-miss criteria.

**Proportion of women who received each number of blood transfusions out of 636 .

MVA, manual vacuum aspiration.

central region of the country. The Eastern region is characterised by a slightly younger age of sexual debut and higher unmet need for family planning which translates to increased unintended pregnancies. ${ }^{22} 3132$ Previous evidence shows that the Eastern region has a huge burden of unintended pregnancies, $8 \%$ of them end in abortions and complications occur in $58 \%$ of the women. ${ }^{22}$ Family planning or postabortion contraception is a key intervention to reduce unintended pregnancies and repeat unsafe abortions respectively, ultimately decreasing ANM and mortality. In addition, access to safe abortion within the confines of the law mitigates the negative effects of unsafe abortion.

Our health facility assessment in the two regions reveals that the Eastern region has less readiness to manage abortion complications such as fewer MVA kits-yet these are 
Table 4 Background indicators, complications and management options of abortion near-miss cases by pregnancy trimester

Abortion near-miss

Column \% (95\% Cl)

Characteristic

First trimesterł $\mathrm{N}=589$

Second trimester§

Prevalence ratio*

$\mathrm{N}=499$

(95\% Cl) P valuet

Background indicators

$27(0.2) \quad 26(0.2)$

0.99 (0.98 to 1.00$)$

0.17

Mean age (SE)

Median no of pregnancies (IQR)

$3(2-6)$

$3(2-5)$

0.99 (0.97 to 1.01$)$

0.48

HIV status

Negative

69 (56 to 79)

70 (56 to 82$)$

Ref

Positive

4 (3 to 8 )

5 (3 to 9)

$1.10(0.83$ to 1.45$)$

0.52

Timing of complications

\begin{tabular}{|c|c|c|c|c|}
\hline At arrival or within 12 hours & 98 (96 to 99$)$ & 95 (92 to 97$)$ & Ref & \\
\hline Developed after 12 hours & $2(1$ to 4$)$ & 5 (3 to 8$)$ & $1.37(1.07$ to 1.76$)$ & 0.01 \\
\hline \multicolumn{5}{|l|}{ Referral status } \\
\hline Not referred & 82 (73 to 88$)$ & 79 (68 to 86$)$ & Ref & \\
\hline Referred & 18 (12 to 27$)$ & 21 (14 to 32 ) & $1.11(0.87$ to 1.42$)$ & 0.40 \\
\hline \multicolumn{5}{|l|}{ Type of health facility } \\
\hline Hospital & 44 (24 to 66$)$ & 52 (28 to 75$)$ & Ref & \\
\hline Health centre & 56 (34 to 76$)$ & 48 (25 to 72$)$ & $0.85(0.61$ to 1.18$)$ & 0.32 \\
\hline \multicolumn{5}{|l|}{ Ownership of health facility } \\
\hline Public & 85 (69 to 94$)$ & 87 (84 to 90$)$ & Ref & \\
\hline Private & $15(6$ to 31$)$ & 13 (5 to 29$)$ & $0.92(0.74$ to 1.14$)$ & 0.44 \\
\hline \multicolumn{5}{|l|}{ Complications and outcome } \\
\hline Infection & 15 (8 to 24$)$ & 17 (10 to 27$)$ & $1.08(0.86$ to 1.37$)$ & 0.49 \\
\hline Organ dysfunction & 80 (68 to 88$)$ & 78 (68 to 86$)$ & $0.96(0.80$ to 1.16$)$ & 0.66 \\
\hline \multicolumn{5}{|l|}{ Management options } \\
\hline \multicolumn{5}{|l|}{ Types of uterine evacuation } \\
\hline Spontaneous expulsion & 37 (20 to 59$)$ & 53 (37 to 69$)$ & Ref & \\
\hline Evacuation/MVA & 62 (41 to 80$)$ & 45 (31 to 60$)$ & 0.69 (0.51 to 0.93$)$ & 0.02 \\
\hline Medical & 0 (0 to 2$)$ & $2(0$ to 7$)$ & 1.49 (0.96 to 2.30$)$ & 0.07 \\
\hline \multicolumn{5}{|l|}{ Uterotonics administered } \\
\hline Misoprostol & 40 (27 to 55$)$ & 43 (29 to 59$)$ & Ref & \\
\hline Oxytocin & 57 (43 to 70$)$ & 55 (39 to 70$)$ & $0.94(0.78$ to 1.15$)$ & 0.55 \\
\hline Other uterotonics & $3(1$ to 10$)$ & $2(1$ to 5$)$ & 0.86 (0.53 to 1.39$)$ & 0.53 \\
\hline \multicolumn{5}{|l|}{ Laparotomy(n=27) } \\
\hline Done $<3$ hours from admission & 25 (3 to 76$)$ & 33 (4 to 85$)$ & Ref & \\
\hline Done $3-12$ hours from admission & 50 (9 to 91$)$ & 50 (10 to 90$)$ & $0.90(0.25$ to 3.23$)$ & 0.85 \\
\hline $\begin{array}{l}\text { Performed after } 12 \text { hours of } \\
\text { admission }\end{array}$ & 25 (3 to 76$)$ & 17 (3 to 60$)$ & $0.75(0.12$ to 4.85$)$ & 0.73 \\
\hline
\end{tabular}

*These are unadjusted prevalence ratio estimates for generalised linear models with binomial family and loglink.

tP value of the prevalence ratio when the null hypothesis of no difference between ANM in first and second trimester for the characteristic is true as extracted from the generalised model.

łProportion of near-miss cases in the first trimester with row characteristic.

§Proportion of near-miss cases in the second trimester with row characteristic.

IHIV status missing for $32 \%(487 / 1507)$ of the near-miss cases.

MVA, manual vacuum aspiration.

critical in removing uterine contents to control bleeding following an abortion. In the event of referral, facilities in the Eastern region are less likely to have motorised transport or a trained health provider accompany the referred woman to a higher health facility. Kananura $e t$ al report a profound lack of abortion services and MVA 
Table 5 Health facility readiness for postabortion care (PAC) in 43 health facilities in central and eastern Uganda

\begin{tabular}{|c|c|c|c|c|}
\hline \multirow[b]{2}{*}{ Indicator } & \multirow{2}{*}{$\begin{array}{l}\text { All health facilities } \\
n(\%) \\
N=43\end{array}$} & \multicolumn{2}{|c|}{ Region n(\%) } & \multirow[b]{2}{*}{ P value* } \\
\hline & & $\begin{array}{l}\text { Central } \\
\mathrm{N}=28\end{array}$ & $\begin{array}{l}\text { Eastern } \\
\mathrm{N}=15\end{array}$ & \\
\hline \multicolumn{5}{|l|}{ Uterotonics } \\
\hline Misoprostol & $18(41.9)$ & $9(32.1)$ & $9(60.0)$ & 0.075 \\
\hline Oxytocin & $37(86.1)$ & $23(82.1)$ & $14(93.3)$ & 0.304 \\
\hline Manual vacuum aspirators & $30(69.8)$ & $24(85.7)$ & $6(40.0)$ & 0.003 \\
\hline Intravenous fluids & $40(93.0)$ & 25 (89.3) & $15(100)$ & 0.541 \\
\hline Parenteral antibiotics & $37(86.1)$ & $25(89.3)$ & $12(80.0)$ & 0.647 \\
\hline Provision of PAC services $24 / 7$ & $43(100)$ & $28(100)$ & $15(100)$ & - \\
\hline Motorised transport for referral & $32(74.4)$ & $25(89.3)$ & $7(46.7)$ & 0.004 \\
\hline Health provider accompanying referral & $18(41.9)$ & $15(53.6)$ & $3(20.0)$ & 0.034 \\
\hline Communication means & $17(39.5)$ & $13(46.4)$ & $4(26.7)$ & 0.207 \\
\hline Blood transfusion services $†$ & $25(64.1)$ & $19(67.9)$ & $6(54.6)$ & 0.297 \\
\hline Surgical/laparotomy capability $†$ & $33(84.6)$ & $25(89.3)$ & $8(72.7)$ & 0.323 \\
\hline
\end{tabular}

The indicators were measured for all 43 health facilities unless otherwise stated.

${ }^{*} \chi^{2}$ or Fischer's exact test done to compare PAC health facility readiness between the central and eastern regions.

†Only assessed for 39 health facilities that offer comprehensive emergency obstetric care services.

sets in 40 health facilities, ranging from Health Centre IIIs to hospitals, from three districts in the same region. ${ }^{33}$ Inability to obtain EmOC at nearby health facilities due to lack of supplies and commodities, non-accompaniment to the next referral site using non-motorised means on bad terrain road infrastructure increases complication rates or death due to delay in accessing appropriate critical care. ${ }^{33-35}$

SAM cases were $42 \%$ in first trimester and $31 \%$ in the second trimester; $2 \%$ of the women with SAM died in second trimester and $0.3 \%$ in the first trimester. The former could reflect the higher frequencies of pregnancies ending in the first trimester than in the second trimester; while the latter agrees with previous studies which show that mortality from abortion complications like bleeding and infection increases with gestation age. $^{36-38}$ The Uganda national reproductive guidelines recommend use of surgical techniques, under general anaesthesia or heavy sedation by doctors for second trimester evacuations. It is worth noting that second trimester near-miss cases were less likely to have uterine evacuation compared with spontaneous expulsion. One possible explanation could be that second trimester abortions tend to be spontaneous hence the complete expulsion. However, it might as well reflect a gap in accessing surgical services overall for abortion cases. Only $85 \%$ of comprehensive EmOC facilities had surgical/laparotomy capability, this may delay patients to receive appropriate surgical care further increasing the severity of the complications with some ending as maternal deaths.

ANM is increased among referrals, who can be identified as high risk cases that require close monitoring. Unlike other studies where majority of maternal near-misses develop either before or at admission, ${ }^{39}$ ANM mainly occurred after 12 hours of admission showing that the cascade of near-miss and mortality can be disrupted if the quality of care is improved and the health facility/providers respond promptly to women who are already in their care.

Despite blood transfusion being a core component of the near-miss classification particularly in a condition such as abortion where massive haemorrhage occurs, over $39 \%$ of transfused patients were discharged with an $\mathrm{Hb}$ less than $70 \mathrm{~g} / \mathrm{L}$ denoting severe anaemia according to WHO recommendations. ${ }^{40}$ With only $64 \%$ of the comprehensive EmOC facilities able to offer blood transfusion services, this study and others in similar settings demonstrate the scarcity of blood products in low and middle income countries. ${ }^{14264142}$ We did not perform a comparative analysis using the WHO near-miss definition of massive transfusion of 5 blood units due to the small number of 17 cases that got a massive transfusion. We had done some more analysis on the cut-off in another paper published from this database. ${ }^{27}$

\section{Strengths and limitations}

A strength of the study is a large data set of over 12800 women from the primary trial with severe maternal morbidity and mortality from 43 health facilities in 18 districts of the country, from which eligible records of those with 3315 severe abortion complications were extracted, enhancing the generalisability of the results. We used the WHO maternal near-miss tool. We modified the data collection tool to include severe abortion complications, ${ }^{43}$ and amended the definition to include all those who received at least two units of blood transfusion. ${ }^{26}{ }^{41}{ }^{42}$ We acknowledge that some researchers cite discrepancies in reporting using modified WHO near-miss tool, however, with a clear reporting of the 
methodology, ${ }^{44}$ we believe that comparison with other studies should be possible. It is the first study to give a detailed description of sociodemographic, reproductive characteristics, clinical presentation and management options for ANM cases by pregnancy trimester. The data collection process lasted a period of 15 months negating effects of variations by seasons unlike most abortion morbidity studies that take a shorter duration, hence more accurate estimates.

The study had some limitations. Data abstraction from patient files may miss some information due to incomplete clinical records, for example, gestation age and HIV status, as cited in other studies. Regular supervision visits were done to provide constant reminders to staff on complete documentation and perform verification with the clinical records and ward registers for the filled tools with subsequent inclusion of the missing information. The data were prospectively collected to reduce risk of missing data. We did not collect information on all abortion cases admitted at these health facilities, so could not ascertain the total number of pregnancies that terminated in the first and second trimesters, and whether the abortions were spontaneous or induced. However, it is worth noting that the recommended standard of reporting ANM is per live births. ${ }^{24}$

\section{Interpretation}

ANM and mortality evidence can be captured using the adapted WHO maternal near-miss criteria particularly in low-income settings. Women with second trimester abortion complications need urgent attention to avert severe abortion-related complications and deaths. Provision of essential drugs and supplies is crucial to averting abortion-related near-miss and deaths. We cannot infer causality as the prospective near-miss and the health facility data come from two different cross-sectional surveys. Still, our analysis indicates that the differences observed between the two settings underscore the importance of quality PAC services to address abortion-related mortality. Appropriately defined studies may further investigate into these associations.

\section{CONCLUSION}

We report an overall high ANMR and AMR, particularly in the Eastern region of the country; and a greater proportion of abortion-related deaths in second trimester. However, mortality is lower compared with studies done in similar settings. ANM is more likely among referrals. The second trimester near-miss is more likely to occur after 12 hours of admission, and less likely to have surgical uterine evacuation. Only three-quarters of health facilities in Uganda that provide comprehensive EmOC have functional blood transfusion services. This coupled with the moderate number of transfused patients at discharge still having severe anaemia shows that use of the adapted WHO near-miss criteria in low-income settings may be more applicable than the strict criteria. ${ }^{27}$ There's a lack of key supplies and commodities, for example, MVA kits, parenteral antibiotics and uterotonics like misoprostol which impede access to appropriate care. Policy-makers should strengthen primary prevention strategies like family planning and harm reduction strategies to reduce the burden of unintended pregnancy and resulting abortion complications. Life-saving drugs and supplies should be available in the health system and referral pathways strengthened to ensure patients access emergency appropriate care early. Finally, abortion maternal death and ANM audit should be implemented and arising recommendations instituted to curtail the vicious cycle of abortion morbidity and mortality.

\section{Author affiliations \\ ${ }^{1}$ Department of Obstetrics and Gynaecology, Makerere University CHS, Kampala, Uganda \\ ${ }^{2}$ Reproductive Endocrinology and Infertility, Mulago Specialised Women and Neonatal Hospital, Kampala, Uganda \\ ${ }^{3}$ Obstetrics and Gynecology, Women's and Children's Health, Stockholm, Sweden ${ }^{4}$ Association of Obstetricians and Gynaecologists of Uganda, Kampala, Uganda ${ }^{5}$ Epidemiology \& Biostatistics, School of Public Health, Makerere University, Kampala, Uganda \\ ${ }^{6}$ Public Health Sciences, Karolinska Institute, Stockholm, Sweden ${ }^{7}$ Dept of Disease Control, London School of Hygiene and Tropical Medicine Faculty of Infectious and Tropical Diseases, London, UK}

Acknowledgements This work was supported through the DELTAS Africa Initiative grant \# DEL-15-011 to THRiVE-2. The DELTAS Africa Initiative is an independent funding scheme of the African Academy of Sciences (AAS)'s Alliance for Accelerating Excellence in Science in Africa (AESA) and supported by the New Partnership for Africa's Development Planning and Coordinating Agency (NEPAD Agency) with funding from the Wellcome Trust grant \# 107742/Z/15/Z and the UK government. The near-miss study was funded through a grant from Laerdal Foundation for acute Medicine (40070) to The International Federation of Gynecology and Obstetrics (FIGO), London, UK.

Contributors SA conceptualised the study, performed data compilation, data analysis, manuscript writing, and was lead author with substantive support from KG-D and CH. FK and JB assisted with study conception and NMT provided statistical input. All coauthors reviewed the draft manuscript versions and approved the final manuscript.

Funding THRiVE-2 - \# DEL-15-011 and FIGO - 40070.

Disclaimer The views expressed in this publication are those of the author(s) and not necessarily those of AAS, NEPAD Agency, Wellcome Trust or the UK government.

Competing interests None declared.

Patient and public involvement statement Patients or the public were not involved in the design, or conduct, or reporting, or dissemination plans of our research.

Patient consent for publication Not required.

Ethics approval Ethical clearance was obtained from Makerere University School of Medicine Research and Ethics Committee (Rec Ref 2017-016) and Uganda National Council for Science and Technology (HS153ES). District Medical Officers, who head the district health management team, gave informed consent at district level and health facility in-charges gave informed consent at health facility level. We did not seek informed consent from individual patients since we abstracted data which were routinely documented. We received ethics approval for this procedure.

Provenance and peer review Not commissioned; externally peer reviewed.

Data availability statement Data are available on request.

Supplemental material This content has been supplied by the author(s). It has not been vetted by BMJ Publishing Group Limited (BMJ) and may not have been peer-reviewed. Any opinions or recommendations discussed are solely those of the author(s) and are not endorsed by BMJ. BMJ disclaims all liability and responsibility arising from any reliance placed on the content. Where the content includes any translated material, BMJ does not warrant the accuracy and reliability 
of the translations (including but not limited to local regulations, clinical guidelines, terminology, drug names and drug dosages), and is not responsible for any error and/or omissions arising from translation and adaptation or otherwise.

Open access This is an open access article distributed in accordance with the Creative Commons Attribution Non Commercial (CC BY-NC 4.0) license, which permits others to distribute, remix, adapt, build upon this work non-commercially, and license their derivative works on different terms, provided the original work is properly cited, appropriate credit is given, any changes made indicated, and the use is non-commercial. See: http://creativecommons.org/licenses/by-nc/4.0/.

Author note Uganda has abortion severe morbidity, near-miss, and mortality ratios of 2063, 938 and 23 per 100000 live births, respectively.

\section{ORCID iDs}

Susan Atuhairwe http://orcid.org/0000-0001-7904-5655

Claudia Hanson http://orcid.org/0000-0001-8066-7873

\section{REFERENCES}

1 Say L, Chou D, Gemmill A, et al. Global causes of maternal death: a who systematic analysis. Lancet Glob Health 2014;2:e323-33.

2 Dragoman M, Sheldon WR, Qureshi Z, et al. Overview of abortion cases with severe maternal outcomes in the who multicountry survey on maternal and newborn health: a descriptive analysis. BJOG 2014;121 Suppl 1:25-31.

3 Sedgh G, Bearak J, Singh S, et al. Abortion incidence between 1990 and 2014: global, regional, and subregional levels and trends. Lancet 2016:388:258-67.

4 Sully EA, Atuyambe L, Bukenya J, et al. Estimating abortion incidence among adolescents and differences in postabortion care by age: a cross-sectional study of postabortion care patients in Uganda. Contraception 2018;98:510-6.

5 Ganatra B, Gerdts C, Rossier C, et al. Global, regional, and subregional classification of abortions by safety, 2010-14: estimates from a Bayesian hierarchical model. Lancet 2017;390:2372-81.

6 Akinlusi FM, Rabiu KA, Adewunmi AA, et al. Complicated unsafe abortion in a Nigerian teaching hospital: pattern of morbidity and mortality. J Obstet Gynaecol 2018;38:961-6.

7 Bankole A, Kayembe P, Chae S, et al. The severity and management of complications among Postabortion patients treated in Kinshasa health facilities. Int Perspect Sex Reprod Health 2018:44:1-9.

8 Borges ALV, OlaOlorun F, Fujimori E, et al. Contraceptive use following spontaneous and induced abortion and its association with family planning services in primary health care: results from a Brazilian longitudinal study. Reprod Health 2015;12:94.

9 Combs Thorsen V, Sundby J, Malata A. Piecing together the maternal death puzzle through narratives: the three delays model revisited. PLoS One 2012;7:e52090.

10 Calvert C, Owolabi OO, Yeung F, et al. The magnitude and severity of abortion-related morbidity in settings with limited access to abortion services: a systematic review and meta-regression. BMJ Glob Health 2018;3:e000692.

11 Say L, Souza JP, Pattinson RC, et al. Maternal near miss--towards a standard tool for monitoring quality of maternal health care. Best Pract Res Clin Obstet Gynaecol 2009;23:287-96.

12 Campbell OMR, Aquino EML, Vwalika B, et al. Signal functions for measuring the ability of health facilities to provide abortion services: an illustrative analysis using a health facility census in Zambia. BMC Pregnancy Childbirth 2016;16:105.

13 Lewis G. Beyond the numbers: reviewing maternal deaths and complications to make pregnancy safer. Br Med Bull 2003;67:27-37.

14 Owolabi OO, Cresswell JA, Vwalika B, et al. Incidence of abortionrelated near-miss complications in Zambia: cross-sectional study in central, Copperbelt and Lusaka provinces. Contraception 2017:95:167-74.

15 Adanikin Al, Umeora O, Nzeribe E, et al. Maternal near-miss and death associated with abortive pregnancy outcome: a secondary analysis of the Nigeria near-miss and maternal death survey. BJOG 2019;126 Suppl 3:33-40.

16 Adler AJ, Filippi V, Thomas SL, et al. Incidence of severe acute maternal morbidity associated with abortion: a systematic review. Trop Med Int Health 2012;17:177-90.

17 Kalilani-Phiri L, Gebreselassie H, Levandowski BA, et al. The severity of abortion complications in Malawi. Int J Gynaecol Obstet 2015;128:160-4.

18 edWorld Health Organization. Safe abortion: technical and policy guidance for health systems. 2nd edn. Geneva, Switzerland, 2012.
19 Ministry of Health U. .. In: National policy guidelines for sexual reproductive health services. 4th edn. Kampala: Reproductive Health Division, Community Health Department, 2011.

20 Klingberg-Allvin M, Cleeve A, Atuhairwe S, et al. Comparison of treatment of incomplete abortion with misoprostol by physicians and midwives at district level in Uganda: a randomised controlled equivalence trial. Lancet 2015;385:2392-8.

21 Paul M, Gemzell-Danielsson K, Kiggundu C, et al. Barriers and facilitators in the provision of post-abortion care at district level in central Uganda - a qualitative study focusing on task sharing between physicians and midwives. BMC Health Serv Res 2014;14:28.

22 Prada E, Atuyambe LM, Blades NM, et al. Incidence of induced abortion in Uganda, 2013: new estimates since 2003. PLoS One 2016;11:e0165812.

23 Hanson C, Pembe AB, Alwy F, et al. Evaluating the effect of the helping mothers survive bleeding after birth (HMS BAb) training in Tanzania and Uganda: study protocol for a randomised controlled trial. Trials 2017;18:307.

24 WHO. Evaluating the quality of care for severe pregnancy complications. WHO Document Production Services, Geneva, Switzerland: The WHO near-miss approach for maternal health, 2011.

25 Sara World Health organization service availability and readiness assessment. version 2.2 December 2014. Available: http://www.who. int/healthinfo/systems/sara_reference_manual/en/ [Accessed 30 Aug 2020].

26 Nelissen E, Mduma E, Broerse J, et al. Applicability of the who maternal near miss criteria in a low-resource setting. PLoS One 2013;8:e61248

27 Pembe AB, Hirose A, Alwy Al-Beity F, et al. Rethinking the definition of maternal near-miss in low-income countries using data from 104 health facilities in Tanzania and Uganda. Int J Gynaecol Obstet 2019;147:389-96.

28 Aantjes CJ, Gilmoor A, Syurina EV, et al. The status of provision of post abortion care services for women and girls in eastern and southern Africa: a systematic review. Contraception 2018;98:77-88.

29 Population GBD, Fertility C, GBD 2017 Population and Fertility Collaborators. Population and fertility by age and sex for 195 countries and territories, 1950-2017: a systematic analysis for the global burden of disease study 2017. Lancet 2018;392:1995-2051.

30 Faúndes A. Strategies for the prevention of unsafe abortion. Int $J$ Gynaecol Obstet 2012;119 Suppl 1:S68-71.

31 Uganda Bureau of Statistcs (UBOS) and ICF. Uganda demographic and health survey 2016: key indicators report. Kampala, Uganda: UBOS, and Rockville, Maryland, USA UBOS and ICF; 2017.

32 Ministry of Health (MoH), United Nations Children's Fund (UNICEF), World Health Organization (WHO), The United Nations Entity for Gender Equality and the Empowerment of Women (UN WOMEN), United Nations Population Fund (UNFPA) and The Joint United Nations Programme on HIV/AIDS (UNAIDS). Adolescent health risk behaviors in Uganda: a national cross-sectional survey. Uganda, 2016.

33 Kananura RM, Kiwanuka SN, Ekirapa-Kiracho E, et al. Persisting demand and supply gap for maternal and newborn care in eastern Uganda: a mixed-method cross-sectional study. Reprod Health 2017;14:136.

34 Waiswa P, Kallander K, Peterson S, et al. Using the three delays model to understand why newborn babies die in eastern Uganda. Trop Med Int Health 2010;15:964-72.

35 Melese T, Habte D, Tsima BM, et al. Management of post abortion complications in Botswana -The need for a standardized approach. PLoS One 2018;13:e0192438.

36 Ziraba AK, Izugbara C, Levandowski BA, et al. Unsafe abortion in Kenya: a cross-sectional study of abortion complication severity and associated factors. BMC Pregnancy Childbirth 2015;15:34.

37 Pestvenidze E, Lomia N, Berdzuli N, et al. Effects of gestational age and the mode of surgical abortion on postabortion hemorrhage and fever: evidence from population-based reproductive health survey in Georgia. BMC Womens Health 2017:17:136.

38 Madziyire MG, Polis CB, Riley T, et al. Severity and management of postabortion complications among women in Zimbabwe, 2016: a cross-sectional study. BMJ Open 2018;8:e019658.

39 Nakimuli A, Nakubulwa S, Kakaire O, et al. Maternal near misses from two referral hospitals in Uganda: a prospective cohort study on incidence, determinants and prognostic factors. BMC Pregnancy Childbirth 2016;16:24

40 WHO. Haemoglobin concentrations for the diagnosis of anaemia and assessment of severity. Geneva: Vitamin and Mineral Nutrition Information System, 2011. https://www.who.int/vmnis/indicators/ haemoglobin.pdf 
41 van den Akker T, van Rhenen J, Mwagomba B, et al. Reduction of severe acute maternal morbidity and maternal mortality in Thyolo district, Malawi: the impact of obstetric audit. PLoS One 2011;6:e20776.

42 Owolabi OO, Biddlecom A, Whitehead HS. Health systems' capacity to provide post-abortion care: a multicountry analysis using signal functions. Lancet Glob Health 2019;7:e110-8.
43 Tura AK, Stekelenburg J, Scherjon SA, et al. Adaptation of the who maternal near miss tool for use in sub-Saharan Africa: an international Delphi study. BMC Pregnancy Childbirth 2017; $17: 445$

44 Tura AK, Trang TL, van den Akker T, et al. Applicability of the who maternal near miss tool in sub-Saharan Africa: a systematic review. BMC Pregnancy Childbirth 2019;19:79. 